\title{
Effects of shade and bird exclusion on arthropods and leaf damage on coffee farms in Jamaica's Blue Mountains
}

\author{
Matthew D. Johnson · Natalee J. Levy • \\ Jherime L. Kellermann · Dwight E. Robinson
}

Received: 21 December 2007/Accepted: 12 December 2008/Published online: 4 January 2009

(C) Springer Science+Business Media B.V. 2009

\begin{abstract}
The effects of overstory trees and birds on coffee pests are poorly understood. This study documents (a) the effect of bird exclusion on foliagedwelling arthropod abundance and insect-caused leaf damage, and (b) the relationships between vegetation complexity and insect abundance, leaf damage, and prevalence of fungal leaf symptoms on coffee farms in the Blue Mountains of Jamaica, West Indies. Overall arthropod abundance was reduced inside bird-proof exclosures, and this corresponded to reduced insect-caused leaf damage. The reduction in leaf damage increased with greater shade, but fungal leaf symptoms increased with greater shade and proximity to non-coffee habitat patches. There appears to be a trade-off for coffee farmers in our study region: vegetation complexity may attract beneficial insect-eating birds that can reduce insect damage, but it is also associated with the prevalence of fungal leaf symptoms.
\end{abstract}

M. D. Johnson $(\bowtie) \cdot$ J. L. Kellermann Department of Wildlife, 1 Humboldt State University, Harpst Street, Arcata, CA 95521, USA

e-mail: mdj6@humboldt.edu

\section{N. J. Levy}

Department of Environmental Sciences, University of California, Berkeley, CA 94720, USA

D. E. Robinson

Department of Life Sciences, University of West Indies, Mona, Jamaica
Keywords Coffee - Bird P Predation .

Biological control $\cdot$ Leaf spot $\cdot$ Ecosystem service

\section{Introduction}

Coffee is one of the most important crops in tropical countries and is second only to oil as the leading legal export in Latin America (O'Brien and Kinnaird 2003; Vandermeer 2003). Insect and fungal pests are the most important factors that limit coffee production in Latin America and the Caribbean (Staver et al. 2001; Soto-Pinto et al. 2000, 2002). Since the 1970s, coffee production has intensified on many farms with the reduction or elimination of shade trees, increased application of agrochemicals, and the use of cultivars tolerant of full sun (Perfecto et al. 1996). Intensification was initially intended to enhance crop production while minimizing damage caused by pests (Staver et al. 2001). However, current understanding of the relationships between overstory shade and pest damage is incomplete and contradictory. Some authors have reported increased pest damage with reduced shade and farm vegetative complexity (Wrigley 1988), while others have documented no significant difference (Soto-Pinto et al. 2000, 2002), or reduced pests with increasing shade (Eskes 1982; Staver et al. 2001; Soto-Pinto et al. 2000, 2002). These patterns combine with non-linear trends in fruit set over varying tree canopy cover, yielding complex region-specific relationships between shade and 
coffee farm production (Beer et al. 1998; Perfecto et al. 2005). A better understanding of shade and pest control is necessary to successfully manage coffee farms for long term productivity and environmental sustainability.

While the relationships between shade and coffee pests appear variable, the correlation between coffee farm vegetative complexity and biodiversity is more predictable and consistent (Donald 2004). Numerous studies have shown that traditionally-managed coffee farms with complex canopies can provide habitat for native plants (Bandeira et al. 2005), insects (Perfecto et al. 1996), mammals (Gallina et al. 1996), and, especially, forest birds attracted to overstory shade trees (Greenberg et al. 1997; Moguel and Toledo 1999; Johnson et al. 2006). Previous work has demonstrated that birds can reduce the abundance of arthropods on coffee shrubs (Greenberg et al. 2000; Perfecto et al. 2004; Borkhataria et al. 2006); recent evidence indicates that birds attracted to vegetatively complex coffee farms may also benefit farmers by reducing short-term infestation rates and damage caused by the coffee berry borer Hypothenemus hampei (Kellermann et al. 2008), the world's most damaging insect pest in coffee (Damon 2000). These pest control services provided by birds could increase farmer income and offer an incentive for farmers to retain overstory trees attractive to insect-eating birds and other native species (Kellermann et al. 2008).

Bird-caused pest control may appear to be a "free pesticide" and a potentially powerful tool for conservation, but the benefits of the suppression of H. hampei by birds could be offset by longer-term impacts to coffee plant health. For example, bird predation may also suppress beneficial general insect predators such as spiders and ants, resulting in a net increase in herbivorous insect abundance and leaf damage. In addition, overstory trees and vegetative complexity attractive to birds may also improve conditions for folivorous insects or fungal pests, which could compromise plant health and reduce crop yield or farm longevity over time. Understanding the relationships between wildlife-friendly agricultural practices, pests, and yield is critical to set policies that can meet production and biodiversity protection targets (Green et al. 2005). To critically evaluate the benefit of shade and birds to farmers, a more complete analysis of potentially confounding effects is necessary.
The objectives of this study were to examine (a) the effect of bird exclusion on foliage-dwelling arthropod abundance and insect-caused leaf damage, and (b) the relationships between vegetation complexity and insect abundance, leaf damage, and prevalence of fungal leaf symptoms on coffee farms in the Blue Mountains of Jamaica, West Indies.

\section{Study site}

The island of Jamaica in the West Indies has approximately 10,000 ha in coffee cultivation. The Blue Mountains of eastern Jamaica yield some of the world's most expensive and sought after coffee (Robinson and Mansingh 1999), with roasted beans bringing up to US US\$80 per pound on international markets.

We selected four farms in the Blue Mountains located within a $10 \mathrm{~km}^{2}$ area (Fig. 1): Clifton Mount (34 ha of coffee), Wallenford (22 ha), McGraham

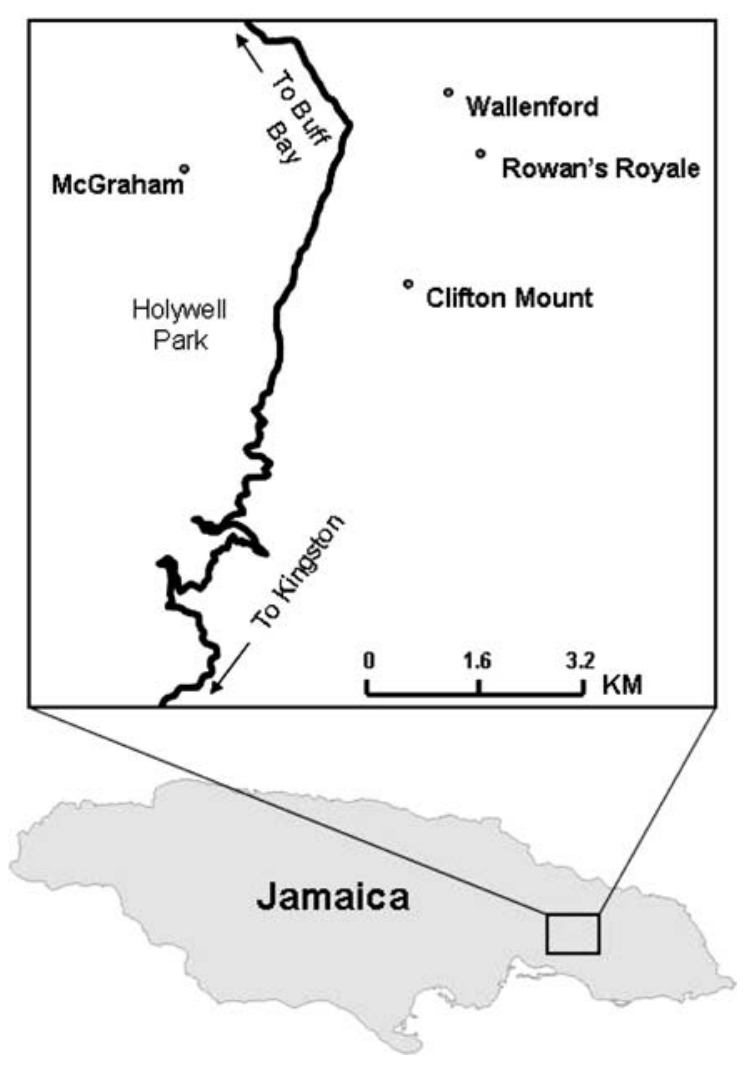

Fig. 1 Map of study region and four study farms 
(6 ha), and Rowan's Royale (0.6 ha). All farms bordered the Blue and John Crow Mountains National Park, represented a range of structural complexity and agricultural intensification within and between farms, grew Coffea arabica var. tipica, and had owners willing to participate in the project. All farms had relatively little shade (averaging $<40 \%$ ) owing to the cool, cloudy climate. An organochloride pesticide (Endosulfan) was applied annually to Clifton Mount, Wallenford, and McGraham in mid to late summer (typically 0.41 of active ingredient/ha), and was not applied again until after project completion. Rowan's Royale is a certified organic farm and was not sprayed.

\section{Methods}

\section{Bird exclosures}

To measure reductions of arthropods by birds, we randomly selected coffee shrub pairs across the four farms (adjusted by farm size; $n=30$ total). We selected experimental coffee shrubs by mapping farm borders with a Geographic Positioning System (GPS, Garmin Ltd, Olathe, KS) and generated random points within that area that were at least $10 \mathrm{~m}$ apart and $10 \mathrm{~m}$ from the farm edge using ArcView 3.3 (ESRI, Redland, CA). The shrub nearest to the random point that was $1.5-2.5 \mathrm{~m}$ tall and flowering or bearing fruit was selected as the experimental shrub and received the bird exclosure. The nearest shrub within 1-5 $\mathrm{m}$ of each experimental shrub that was visually assessed to be similar in form and production was selected as a control plant. Exclosures on Wallenford $(n=10)$ and Rowan's Royale ( $n=5$ ) were built in late November 2005; exclosures on Clifton Mount $(n=10)$ and McGraham $(n=5)$ were built in early January 2006. Our construction of exclosures coincided with the commencement of the asynchronous fruit emergence on the farms. Once erected, exclosures were left up continuously until November 2006.

Exclosures were pyramidal-style pole frames of $5 \mathrm{~m}$ cut saplings over individual coffee shrubs, wrapped in transparent nylon gill netting (N163A $58 \mathrm{~mm}$ mesh, Nylon Net Co., Memphis TN, USA), tied shut, and staked down to prevent entry of ground foraging birds. A $58 \mathrm{~mm}$ mesh size does not restrict access by Anolis lizards or invertebrates (Borkhataria et al. 2006). Foliage-gleaning bats, which were also excluded by our experimental design, can also influence arthropod abundance (Williams-Guillén et al. 2008). However, in Jamaica no bat species is considered primarily a foliage-gleaner, though Macrotus waterhousii occasionally gleans insects from foliage (Genoways et al. 2005). This species is larger than most foliage-gleaning birds in our system (16-20 g) and is unlikely to take prey $<5 \mathrm{~mm}$ (S. Koenig, personal communication).

\section{Arthropod sampling}

Arthropod samples were collected from each exclosure and control shrub in summer (19-22 June) and fall (20-25 November) 2006. Two samples were taken from each shrub, at a height of 1-1.5 m, from opposite sides of the shrub at aspects perpendicular to the coffee row. Height and aspect of all samples were recorded, but data did not differ significantly among heights, aspects, or between the two samples within a shrub, so samples were pooled for analyses. On exclosures, a hole $\left(\sim 0.36 \mathrm{~m}^{2}\right)$ was cut in the mesh for each sample, and retied shut after sampling was complete. All samples were collected between 9:00 and 14:00 CST. Arthropods were sampled by quickly placing a plastic bag (49 1) over one to several coffee branches, closing the bag around the branches, clipping them, dropping two acetone-soaked cotton balls into the bag, and tying the bag shut. Our intent was to sample the same volume for each sample. After at least $2 \mathrm{~h}$, the contents of each bag were sorted, and each arthropod was identified to order (except Hemiptera was split into Heteroptera and other suborders; Hymenoptera was split into Formicidae and other families) and measured in length to the nearest milimeter. Coffee foliage density is variable, and samples of similar volume had different numbers of branches. Therefore, the vegetative contents of each sample were weighed to the nearest gram, and arthropod abundance was divided by this weight to standardize different sized samples. Samples were weighed immediately after sampling in the field; they were not dried. Wet weight was used rather than dry weight for ease of field procedures. All arthropod data were natural-log transformed to meet assumptions of normality.

We had a total of 30 exclosures and 30 control shrubs, but various circumstances reduced our available sample size. Arthropod abundance could not be sampled at Wallenford $(n=10)$ in June because it had been sprayed with insecticide shortly before our 
planned insect sampling; the other farms had not been sprayed for at least 9 months before sampling. In addition, one exclosure-control pair on the Clifton Mount farm was not sampled in June due to accessibility constraints (yielding $n=19$ exclosure and 19 control samples for the June sampling). In November, all farms were sampled, but seven exclosure-control pairs had been damaged on the Clifton Mount farm and were excluded from analysis (yielding $n=23$ exclosure and 23 control samples). The November samples were completed at least three months after insecticide application on the three non-organic farms. Analyses (ANOVA; see below) were separated by sampling and did not require equal sample sizes among factors.

\section{Leaf surveys}

We surveyed for evidence of insect herbivory and fungal leaf spots in June 2006. We visually inspected two hundred leaves systematically sampled from four cardinal directions and upper and lower vertical strata of each exclosure and control shrub. We recorded the proportion of leaves that showed evidence of insect herbivory (e.g., chewed leaf margins, mines, etc.). We did not quantify the degree of herbivory within a leaf or search other plant structures (e.g., fruits or stems) for evidence of herbivory, so our estimates are minimum estimates of the prevalence of damage. We also recorded the proportion of leaves that contained evidence of leaf spot disease. Brown leaf spot (Cercospora coffeicola) and American leaf spot (Mycena citricolor) are both common in many coffee-growing regions (LePelley 1973), including the Blue Mountains of Jamaica (Budhlall 1986), and they are easily recognized as "eyespots" on leaf surfaces. We did not distinguish between these two species, nor did we survey other plant structures, so our data provide minimum estimates of leaf spot prevalence. One exclosure-control pair on the Clifton Mount farm was not sampled due to accessibility constraints (yielding $n=29$ exclosure and 29 control samples). The prevalence of insect-caused leaf damage and fungal leaf spots were natural-log transformed $(+1)$ to meet normality assumptions.

\section{Vegetation complexity}

We considered vegetation complexity to be a physiognomic measure of vegetation cover, shade, tree size, and distribution of non-coffee habitat within and adjacent to coffee farms. Within $400 \mathrm{~m}^{2}$ plots centered on each exclosure, we measured percent shade cover (see below), number of coffee shrubs $(\geq 1 \mathrm{~m})$, number of banana plants $(\geq 1 \mathrm{~m})$, and number, average height, and average diameter at breast height (dbh) of shade trees. We used two methods to measure shade and overstory tree cover. A densiometer (Forestry Suppliers Inc., Jackson, MS, USA) was used to measure vegetative cover directly overhead of each plot by taking one reading at the north side of the exclosure and one at each cardinal direction $5 \mathrm{~m}$ from the exclosure and averaging them. We also used a solar pathfinder (Solar Pathfinder, Linden, TN, USA), to measure total annual solar insulation/percent shade at each exclosure and control shrub, which we averaged to characterize each plot.

To further assess vegetation complexity, we estimated the linear distance from each exclosure to the nearest tree, habitat patch, and farm edge vegetation within four $90^{\circ}$ arcs centered on each cardinal bearing. We used visual estimation and a hand-held laser rangefinder to estimate distances. We defined a tree as any woody, non-coffee plant $>5 \mathrm{~m}$ tall and a habitat patch as an area $\geq 10 \mathrm{~m}^{2}$ of woody non-coffee vegetation with elements $>5 \mathrm{~m}$ tall, both of which birds can use as "stepping stones" to move through highly disturbed areas (Wunderle 1999). We created six variables for each plant pair: the single nearest distance to each vegetation component (nearest tree, patch, edge) and the average distance to each component across all four directions (average tree, patch, edge). Nearest tree, patch, and edge were square root transformed and average distance to tree was natural-log transformed to meet normality assumptions. Average patch and edge did not require transformations. All vegetation measurements were made coincident with the arthropod sampling, in June and November 2006. No pruning of non-coffee habitat occurred, except some banana plants were cut back after fruiting.

Data analysis

We used 2-way ANOVAs to examine the effects of bird exclusion on arthropod abundance, with shrub type (exclosure vs. control) and farm (Wallenford, Clifton Mount, McGraham, and Rowan's Royale) as factors. We ran analyses for small $(\leq 5 \mathrm{~mm})$, large 
( $>5 \mathrm{~mm}$ ), and total arthropods separately for summer (June) and fall (November) 2006. We also tested for effects of exclosures and farm on the abundance of spiders (Aranae) and ants (Formicidae) in particular. We also used 2-way ANOVA to examine effects of bird exclusion on the prevalence of insect-caused leaf damage. We used $\chi^{2}$ analyses to compare the composition of the arthropod community among shrub types (exclosure, control), dates (summer, fall), and farms.

To examine relationships between insect abundance, leaf damage, and vegetation variables, we used general linear models. Where necessary, continuous variables were natural-log or square root transformed to meet assumptions of normality. Farm was included as a categorical predictor variable. Because vegetation data varied little between an exclosed shrub and its control, we used data from exclosed plants only as the response variable to avoid pseudoreplication. In some cases, we used the difference between exclosure and control plants as the response variable (e.g., to ask if the magnitude of bird exclusion on arthropods varied with vegetative complexity). Many of the vegetation measures we collected represent different manners of sampling similar habitat characteristics (e.g., percent shade from densiometer and solar pathfinder). To avoid including collinear variables in regression models, we entered all dependent variables with all independent vegetation complexity variables into a Spearman rank correlation matrix (Greaves et al. 2006). We first chose the variable with the highest Spearman rank correlation coefficient for each dependent variable and then eliminated all independent variables that were collinear $(|r|>0.50)$ with the selected variable. We repeated this process with the remaining independent variables until we established a subset, which was then entered into forward stepwise general linear model (alpha $=0.15$ to enter, Anderson et al. 2000). All analyses were run in SPSS 13.0 (SPSS Inc 2004) with an alpha value of 0.05 . Descriptive statistics are reported as untransformed means $\pm 1 \mathrm{SE}$.

\section{Results}

Effect of bird exclusion on insects

In summer, small $\left(F_{1,32}=6.21, P=0.018\right)$, large $\left(F_{1,32}=6.91, \quad P=0.013\right)$, and total arthropods

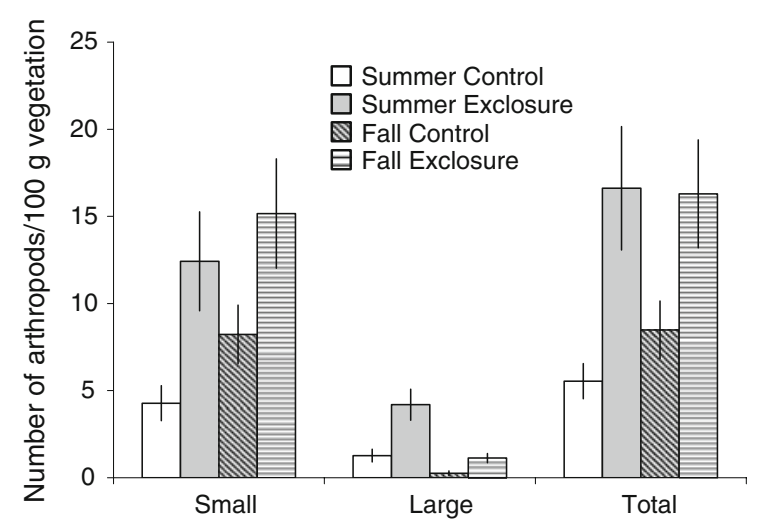

Fig. 2 Mean number of small $(\leq 5 \mathrm{~mm})$, large $(>5 \mathrm{~mm})$, and total arthropods $( \pm 1 \mathrm{SE})$ inside and outside bird exclosures on four farms in Jamaica's Blue Mountains (summer = June 2006, Fall $=$ November 2006)

$\left(F_{1,32}=7.70, P<0.009\right)$ were significantly more abundant inside exclosures than on control shrubs (66, 70, and 67\% reductions, respectively, Fig. 2). There were no effects of farm (all $F_{2,32}<2.04$, $P>0.14)$, nor any interactions between farm and shrub type (all $F_{2,32}<1.29, P>0.28$ ). The abundance of spiders was reduced by $62 \%\left(F_{1,32}=9.41\right.$, $P=0.004)$, but there was no significant effect on ants $\left(F_{1,32}=2.47, P=0.126\right)$. Neither spiders nor ants showed any significant variation by farm or the interaction between farm and shrub type (all $P$ s $>0.095)$.

In fall, the abundance of large (77\% reduction, $\left.F_{1,38}=7.97, P=0.008\right)$ and total arthropods (48\% reduction, $\left.F_{1,38}=4.29, P=0.045\right)$ was reduced outside of the exclosures, but small arthropods had statistically similar abundances inside and outside exclosures $\left(F_{1,38}=2.94, P=0.094\right)$. The abundance of small and total arthropods varied significantly among farms $\left(F_{3,38}=3.11, P=0.038\right.$, and $F_{3,38}=3.50, \quad P=0.024$, respectively), with abundances lower on Rowan's Royale and McGraham than on Clifton Mount and Wallenford. Large arthropod abundance was similar across farms $\left(F_{3,38}=1.68, P=0.187\right)$, and there were no significant interactions between farm and shrub type (all $\left.F_{3,38}<2.09, P>0.119\right)$. The abundance of spiders and ants did not vary significantly by shrub type, farm, or their interactions (all $P \mathrm{~s}>0.18$ ).

The arthropod community composition did not vary significantly among dates or farms. Overall, Aranae (spiders), Hemiptera (e.g., leafhoppers), 
Coleoptera (beetles), and Formicidae (ants) comprised over $80 \%$ of all sampled arthropods. However, the proportional composition of the arthropod community varied significantly between exclosure and control shrubs $\left(\chi^{2}=54.4, \quad d f=11, \quad P<0.0001\right.$, Table 1). Coleoptera comprised $17 \%$ of all arthropods on control shrubs, but only $9 \%$ on exclosure shrubs. Conversely, Formicidae made up a larger proportion of the community on exclosure shrubs (22\%) than on control shrubs (7\%). The other taxa showed similar proportions between exclosure and control shrubs (all $\leq 3 \%$ difference).

\section{Leaf survey results}

Insect-caused leaf damage was less prevalent on control shrubs than inside exclosures (28\% reduction; $F_{1,50}=18.82, \quad P<0.001, \quad$ Fig. 3). Leaf damage tended to be higher overall on Rowan's Royale than on the other farms, but this difference was not statistically significant $\left(F_{3,50}=2.54, P=0.067\right)$. There was no interaction between shrub type and farm $\left(F_{3,50}=0.13, P=0.939\right)$. There was no effect of exclosures on the prevalence of leaf spot $\left(F_{1,50}=0.13, P=0.718\right)$, but leaf spot was significantly more prevalent at Rowan's Royale than on the other farms $\left(F_{3,50}=19.53, P<0.001\right.$, Fig. 3$)$.

Table 1 Percentages of arthropod taxa sampled from inside and outside bird exclosures in Jamaica's Blue Mountains, 2006

\begin{tabular}{lrr}
\hline Taxon & Control shrubs & Exclosure shrubs \\
\hline Aranae & 9 & 7 \\
Orthoptera & 3 & 3 \\
Blattaria & $<1$ & $<1$ \\
Heteroptera & 2 & 1 \\
Other Hemiptera & 46 & 46 \\
Coleoptera & 17 & 9 \\
Lepidoptera & 1 & 1 \\
Diptera & 4 & 2 \\
Formicidae & 7 & 22 \\
Other Hymenoptera & 4 & 3 \\
Psocoptera & 7 & 4 \\
Neuroptera & $<1$ & $<1$ \\
Total number of arthropods & 323 & 954
\end{tabular}

Composition did not vary significantly among farms or between summer and fall, so data were pooled for analysis

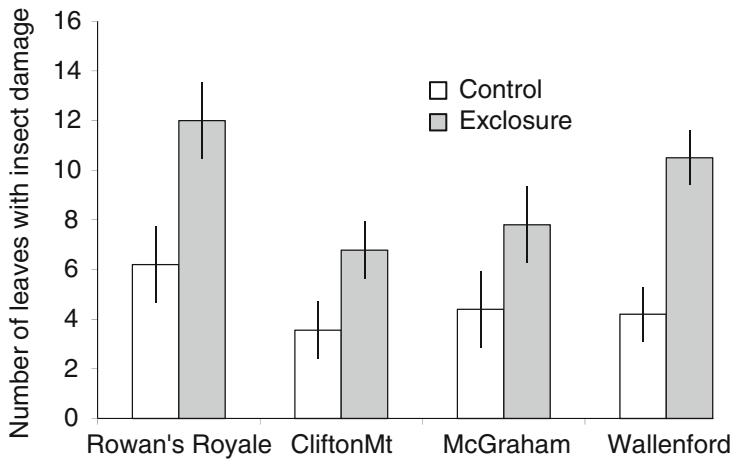

Fig. 3 Mean number $( \pm 1 \mathrm{SE})$ of leaves with insect damage (out of 200 inspected) inside and outside bird exclosures on four farms in Jamaica's Blue Mountains (June 2006)

\section{Relationships with vegetation complexity}

Vegetation complexity varied significantly within and among farms (Table 2). In general, Rowan's Royale had the most vegetative complexity, and Wallenford had the least. There were no significant relationships between any vegetation variable and overall arthropod abundance in summer or fall. Likewise, there were no significant relationships between vegetation and the difference in arthropods between exclosures and control shrubs. However, the difference in leaf damage between exclosure and controls shrubs was positively correlated with the distance to the nearest patch and shade cover (as measured with solar pathfinder), and negatively associated with the number of coffee shrubs $\left(F_{3,38}=7.41, \quad P=0.001\right.$, $\left.\mathrm{R}^{2}=0.369\right)$. The prevalence of leaf spot showed a statistically significant increase with percent shade (natural-log transformed), and an increase with proximity of the nearest non-coffee habitat patch $\left(F_{2,28}=7.48, P=0.001, \mathrm{R}^{2}=0.403\right.$, Fig. 4$)$.

\section{Discussion}

This study suggests that vertebrate predation significantly reduced overall arthropod abundance on coffee plants (Fig. 2). The vast majority of this effect was probably due to birds, since lizards were not excluded by our exclosures, and few bats glean insects from understory foliage in Jamaica. The effect of predation was strongest for large arthropods, and for samples taken in summer. A disproportionate effect on large arthropods is expected given birds' preference for 
Table 2 Descriptive statistics (mean $\pm 1 \mathrm{SE}$ ) of vegetation complexity measured on $400 \mathrm{~m}^{2}$ sampling plots on four coffee farms in Jamaica's Blue Mountains

\begin{tabular}{|c|c|c|c|c|c|c|}
\hline Vegetation variable & $\begin{array}{l}\text { Clifton Mt. } \\
(n=9)\end{array}$ & $\begin{array}{l}\text { Wallenford } \\
(n=10)\end{array}$ & $\begin{array}{l}\text { McGraham } \\
(n=5)\end{array}$ & $\begin{array}{l}\text { Rowan's Royale } \\
(n=5)\end{array}$ & $F_{3,28}$ & $P$ \\
\hline Overstory cover ${ }^{\mathrm{a}}$ & $38.4 \pm 10.0$ & $0.2 \pm 0.1$ & $35.7 \pm 10.8$ & $34.7 \pm 8.0$ & 6.79 & 0.002 \\
\hline Shade $^{\mathrm{b}}$ & $18.6 \pm 9.9$ & $0 \pm 0$ & $15.5 \pm 7.1$ & $31.2 \pm 6.7$ & 3.39 & 0.034 \\
\hline Coffee density ${ }^{c}$ & $40.2 \pm 5.7$ & $27.1 \pm 3.3$ & $42.2 \pm 4.2$ & $36.8 \pm 3.9$ & 2.39 & 0.093 \\
\hline Banana density ${ }^{\mathrm{c}}$ & $1.9 \pm 0.8$ & $0 \pm 0$ & $6.4 \pm 3.4$ & $14.2 \pm 6.5$ & 5.60 & 0.004 \\
\hline Distance to edge $^{\mathrm{d}}(\mathrm{m})$ & $118.9 \pm 19.7$ & $104.3 \pm 11.1$ & $66.1 \pm 12.3$ & $53.2 \pm 2.7$ & 3.71 & 0.025 \\
\hline Distance to patch $^{\mathrm{d}}(\mathrm{m})$ & $87.2 \pm 15.6$ & $95.1 \pm 12.2$ & $52.0 \pm 8.8$ & $53.2 \pm 2.7$ & 2.60 & 0.075 \\
\hline Distance to tree $^{\mathrm{d}}(\mathrm{m})$ & $17.8 \pm 3.5$ & $84.7 \pm 5.5$ & $19.7 \pm 4.3$ & $17.2 \pm 3.7$ & 56.66 & $<0.001$ \\
\hline
\end{tabular}

a As measured with a densiometer (\% cover)

b As measured with a solar pathfinder (mean annual percent solar radiation obscured by shade)

c Number of coffee shrubs or banana trees per $400 \mathrm{~m}^{2}$ plot

${ }^{\mathrm{d}}$ Distance $(\mathrm{m})$ from exclosure at plot center to the nearest farm edge, non-coffee habitat patch, or overstory tree averaged across four cardinal directions. Values for the single nearest of each of these elements to each sample point showed similar patterns

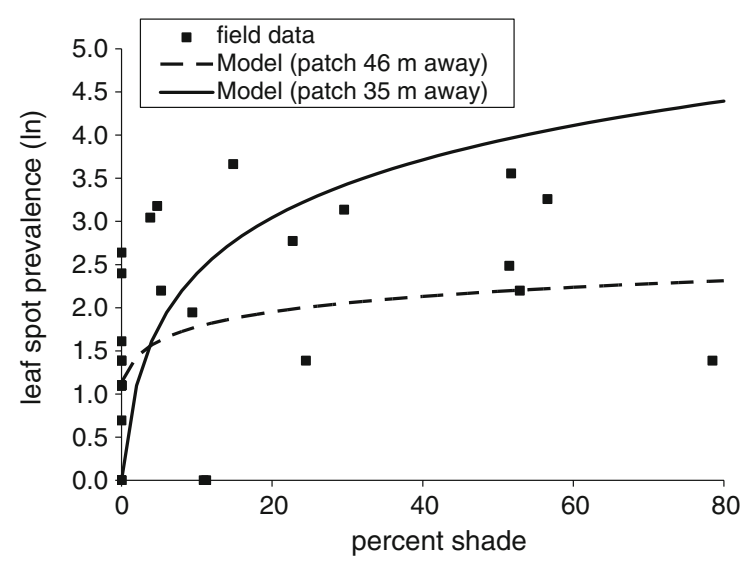

Fig. 4 Field data and regression model predicting relationship between the prevalence of leaf spot fungi and percent shade cover (measured with solar pathfinder) on four coffee farms in Jamaica's Blue Mountains (June 2006). Shade cover was natural-log transformed for analysis, but is depicted on a linear scale in the figure, yielding an asymptotic curve for the regression model. Model curves are shown for two example values of the distance to a non-coffee patch, which was also a significant variable in the model

more profitable prey especially in the breeding season (Johnson et al. 2005), and is consistent with other bird exclosure experiments (Van Bael et al. 2008). The number of birds in Jamaica is much higher in the fall than in the summer due to the arrival of migrant birds from North America (Johnson et al. 2005), so our finding that the effect of birds was stronger in summer than fall was unexpected. However, the seasonal distribution of birds among coffee farms and adjacent uncultivated patches is unknown in the Blue Mountains, and could influence local predator abundance more strongly than island-wide variation in bird numbers. In addition, residual effects of insecticides are more likely to be present in our fall data (3 months post-application) than in our summer data ( 9 months post-application).

Top-down effects of vertebrate predators on arthropods can be complicated by predation within the arthropod community and meso-predator releases (Philpott et al. 2004; Borkhataria et al. 2006). Although our results showed that all taxonomic groups declined in abundance in the presence of bird predation, the composition of the arthropod community shifted (Table 1), with proportionately fewer ants and more beetles where birds had access to arthropods (control shrubs). It is unknown whether this is due to preferential predation on ants or an interaction within the arthropod community (Philpott et al. 2004), or another unmeasured environmental variable. Although temperature and relative humidity were similar inside and outside exclosures (Kellermann et al. 2006), other environmental factors could have varied between exclosure and control shrubs that in turn affected arthropod community composition. Regardless, the net effect was a reduction of all arthropods, including both herbivorous and carnivorous groups. Thus, our results expand upon those by Borkhataria et al. (2006), who found that birds helped control insect populations without exacting a cost in the form of reduced abundance of beneficial arthropods. The reductions in 
overall arthropods we documented (48-77\%) are consistent with other bird exclosure experiments in other temperate (Holmes et al. 1979) and tropical systems (Greenberg et al. 2000; Van Bael et al. 2008). It is important to note that the abundance of small and total arthropods in the summer was lower on the two smallest farms in the study, so landscape or colonization effects on arthropod abundance are a possibility.

The reduction of arthropods corresponded to less insect-caused damage to coffee leaves on control shrubs than on exclosure shrubs (Fig. 3). Reduced endemic levels of herbivory may over time limit the need for plants to synthesize higher concentrations of alkaloids and produce tougher leaves (Frischnecht et al. 1986; Greenberg et al. 2000) that can impose considerable cost to the plant (Coley et al. 1985). Reduced herbivory, coupled with a direct reduction of fruit-damaging pests (Kellermann et al. 2008), demonstrates an ecosystem service (Daily 1997; Şekercioğlu et al. 2004) provided by birds to coffee farms. The economic implications of pest reduction are significant (Kellermann et al. 2008), but the long term economic effects of reduced herbivory have not been established (Greenberg et al. 2000).

We found no significant relationships between measures of vegetation complexity and arthropod abundance, the reduction of arthropods, and insectcaused leaf damage, despite considerable variation in vegetation both between and within our study farms (Table 2). Birds are well known to increase in abundance with coffee farm complexity in general (Donald 2004), and on our study farms in particular (Kellermann et al. 2008). Insect-caused leaf damage decreased with increasing shade, but there were no inverse relationships between farm complexity and arthropod abundance or reduction in arthropods by birds. This may be because mobile agents such as birds can provide ecosystem services to areas beyond their primary habitats (Kremen et al. 2007). Many species of small insectivorous birds in the tropics are habitat generalists, especially the migratory species (Wunderle and Waide 1993), and birds may track insect abundance across habitats (Johnson and Sherry 2001). The comparatively small size of the farms in our study (0.6-34 ha) coupled with the diversity of neighboring land parcels and the capacity for birds to move among habitat patches may dilute negative effects of intense agricultural practices on pest control serviced provided by insect-eating birds
(Altieri 1999). Further research is urgently needed to examine the relationship between landscape heterogeneity, forest loss, and the erosion of ecosystem services provided by organisms partly reliant on nonagricultural habitats (Preiss et al. 2007).

It is important to note that our assessment of vegetation complexity did not consider plant species composition or diversity, a significant factor in avian presence and utilization of coffee farms (Perfecto et al. 2004). The farms in our study region mostly utilized native tree species for shade cover such as Blue Mahoe (Hibiscus elatus) and Dovewood (Alchornea latifolia) mixed with some non-native species including Caribbean Pine (Pinus caribbea) and mango (Mangifera spp.) In order to optimize the attractiveness of a farm to beneficial birds, species composition of the planned and unplanned crop and non-crop biodiversity on farms should be considered (Perfecto and Vandermeer 2002).

The prevalence of leaf spot symptoms on coffee leaves was highly variable, but it increased asymptotically with shade cover and decreased linearly with distance to the nearest non-coffee habitat patch (Fig. 4). That is, greater vegetative complexity was loosely correlated with increasing fungal disease symptoms. Conversely, bird abundance is generally associated with greater vegetative complexity (Komar 2006) and was positively correlated with shade cover and negatively correlated with distance to the nearest non-coffee habitat patch in our study area (Kellermann et al. 2008). Thus, there appears to be a trade-off for coffee farmers in our study region: vegetative complexity may attract beneficial insect-eating birds that can reduce insect damage, but it is also associated with the prevalence of fungal disease symptoms. The availability of fungal pesticides could influence this trade-off, tipping the balance in favor of greater shade, but financial and environmental costs of fungicide use should be better understood. The relationship between shade cover and coffee yield in the Blue Mountains is unknown, but yield peaks between 38 and $48 \%$ shade at similar elevations on coffee farms in Mexico (800$1,200 \mathrm{~m}$ asl, Soto-Pinto et al. 2000). However, numerous environmental and shade-management practices differ between Jamaica and Mexico. Further research should investigate trade-offs in production and natural pest control associated with farm complexity in intermediate ranges of tree shade cover that maximize yield, and additional region-specific work is 
needed. Most countries in Latin America, including Jamaica, are regulating or prohibiting the use of aggressive organochlorine insecticides such as Endosulfan (PANAP 1996). As their use diminishes, the industry will need a better understanding of more environmentally-friendly approaches to integrated pest management. Our results suggest bird consumption of insects should be a component of that future work to better articulate relationships between shade, pests, and coffee yield.

Acknowledgments This project would not have been possible without the cooperation of the farmers: D. Campbell, D. McGraham, J. Sharpe, R. Sharpe, and Wallenford Coffee Company. We also thank The Coffee Industry Board of Jamaica, the Jamaica Conservation and Development Trust, and Jamaica's National Environment and Planning Agency for cooperation. Funding was provided by American Museum of Natural History, Cooper Ornithological Society, Humboldt State University, National Geographic Society, the US Fish and Wildlife Service, and the National Science Foundation (HSU IACUC number \# 05/06.W.06.E).

\section{References}

Altieri MA (1999) The ecological role of biodiversity in agroecosystems. Agric Ecosyst Environ 74:19-31. doi: 10.1016/S0167-8809(99)00028-6

Anderson DR, Burnham KP, Thompson WL (2000) Null hypothesis testing: problems, prevalence, and an alternative. J Wildl Manag 64:912-923. doi:10.2307/3803199

Bandeira FP, Martorell C, Meave JA, Caballero J (2005) The role of rustic coffee plantations in the conservation of wild tree diversity in the Chinantec region of Mexico. Biodivers Conserv 14:1225-1240. doi:10.1007/s10531-0047843-2

Beer J, Muschler R, Kaas D, Somarriba E (1998) Shade management in coffee and cacao plantations. Agrofor Syst 38:139-164. doi:10.1023/A:1005956528316

Borkhataria RR, Collazo JA, Groom MJ (2006) Additive effects of vertebrate predators on insects in a Puerto Rican coffee plantation. Ecol Appl 16:696-703. doi:10.1890/10510761(2006)016[0696:AEOVPO]2.0.CO;2

Budhlall PE (1986) Growing coffee in Jamaica. Coffee Industry Development Company, Kingston

Coley PD, Bryant JP, Stuart Chapin FIII (1985) Resource availability and plant arthropod defense. Science 230:895-899. doi:10.1126/science.230.4728.895

Daily GC (1997) Nature's services. Island Press, Washington

Damon A (2000) A review of the biology and control of the coffee berry borer, Hypothenemus hampei (Coleoptera: Scolytidae). Bull Entomol Res 90:453-465. doi:10.1017/ S0007485300000584

Donald PF (2004) Biodiversity impacts of some agricultural commodity production systems. Conserv Biol 18:17-37. doi:10.1111/j.1523-1739.2004.01803.x
Eskes AB (1982) The effect of light intensity on incomplete resistance of coffee to Hemileia vastrix. Neth J Plant Pathol 88:191-202. doi:10.1007/BF02140882

Frischnecht PM, Dufek JV, Baumann TW (1986) Purine alkaloid formation in buds and developing leaflets of Coffea arabica. Phytochemistry 5:613-616. doi:10.1016/00319422(86)88009-8

Gallina S, Mandujano S, González-Romero A (1996) Conservation of mammalian biodiversity in coffee plantations of Central Veracruz, Mexico. Agrofor Syst 33:13-27

Genoways HH, Baker RJ, Bickham JW, Phillips CJ (2005) Bats of Jamaica. Special Publications of the Museum of Texas Tech University 48

Greaves RK, Sanderson RA, Rushton SP (2006) Predicting species occurrence using information-theoretic approaches and significance testing: An example of dormouse distribution in Cumbria, UK. Biol Conserv 130:239-250. doi:10.1016/j.biocon.2005.12.017

Green RE, Cornell SJ, Scharlemann JPW, Balmford A (2005) Farming and the fate of wild nature. Science 307(5709):550-555. doi:10.1126/science.1106049

Greenberg R, Bichier P, Angon AC, Reitsma R (1997) Bird populations in shade and sun coffee plantations in central Guatemala. Conserv Biol 11:448-459. doi:10.1046/j.15231739.1997.95464.X

Greenberg R, Bichier P, Angon AC, MacVean C, Perez R, Cano E (2000) The impact of avian insectivory on arthropods and leaf damage in some Guatemalan coffee plantations. Ecology 81:1750-1755

Holmes RT, Schultz JC, Nothnagle P (1979) Bird predation on forest insects: an exclosure experiment. Science 206:462463. doi: $10.1126 /$ science. 206.4417 .462

Johnson MD, Sherry TW (2001) Effects of food availability on the distribution of migratory warblers among habitats in Jamaica. J Anim Ecol 70:546-560. doi:10.1046/j.13652656.2001.00522.x

Johnson MD, Sherry TW, Strong AM, Medori A (2005) Migrants in Neotropical bird communities: an assessment of the breeding currency hypothesis. J Anim Ecol 74:333341. doi:10.1111/j.1365-2656.2005.00928.x

Johnson MD, Sherry TW, Holmes RT, Marra PP (2006) Measuring habitat quality for a migratory songbird wintering in natural and agricultural areas. Conserv Biol 20:1433-1444. doi:10.1111/j.1523-1739.2006.00490.x

Kellermann JL, Johnson MD, Stercho A, Hackett SL (2008) Ecological and economic services provided by birds on Jamaican Blue Mountain coffee farms. Conserv Biol 22:1177-1185. doi:10.1111/j.1523-1739.2008.00968.x

Komar O (2006) Ecology and conservation of birds in coffee plantations: a critical review. Bird Conserv Int 16:1-23. doi:10.1017/S0959270906000074

Kremen C, Williams NM, Aizen AM, Gemmill-Herren B, LeBuhn G, Minckley R, Packer L, Potts SG, Roulston T, Steffan-Dewenter I, Vázquez DP, Winfree R, Adams L, Crone EE, Greenleaf SS, Keitt TH, Klein AM, Regetz J, Ricketts TH (2007) Pollination and other ecosystem services produced by mobile organisms: a conceptual framework for the effects of land-use change. Ecol Lett 10:299-314. doi:10.1111/j.1461-0248.2007.01018.x

LePelley RH (1973) Coffee insects. Annu Rev Entomol 18:121-142. doi:10.1146/annurev.en.18.010173.001005 
Moguel P, Toledo VM (1999) Biodiversity conservation in traditional coffee systems of Mexico. Conserv Biol 13:11-21. doi:10.1046/j.1523-1739.1999.97153.x

O'Brien TG, Kinnaird MF (2003) Caffeine and conservation. Science 300(5619):587. doi:10.1126/science.1082328

PANAP (1996) Endosulfan datasheet. Pesticide action network-asia and the pacific. Penang, Malaysia, p 6 June 1996

Perfecto I, Vandermeer J (2002) Quality of agroecological matrix in a tropical montane landscape: ants in coffee plantations in southern Mexico. Conserv Biol 16:174182. doi:10.1046/j.1523-1739.2002.99536.x

Perfecto IP, Rice RA, Greenberg R, Van Der Voort ME (1996) Shade coffee: a disappearing refuge for biodiversity. Bioscience 46:598-608. doi:10.2307/1312989

Perfecto I, Vandermeer JH, López G, Ibarra-Nuñez G, Greenberg R, Bichier P, Langridge S (2004) Greater predation of insect pests in a diverse agroecosystem: the role of resident Neotropical birds in shade coffee farms. Ecology 85:2677-2681. doi:10.1890/03-3145

Perfecto I, Vandermeer J, Masa A, Soto-Pinto L (2005) Biodiversity, yield, and shade coffee certification. Ecol Econ 54:435-446. doi:10.1016/j.ecolecon.2004.10.009

Philpott SM, Greenberg R, Bichier P, Perfecto I (2004) Impacts of major predators on tropical agroforest arthropods: comparisons within and across taxa. Oecologia 140:140149. doi:10.1007/s00442-004-1561-z

Preiss JA, Mimler M, Klein A-M, Schwarze S, Tscharntke T, Steffan-Dewenter I (2007) Linking deforestation scenarios to pollination services and economic returns in coffee agroforestry systems. Ecol Appl 17:407-417. doi:10.1890/ 05-1795

Robinson DE, Mansingh A (1999) Insecticide contamination of the Jamaican Environment IV. Transport of residues from coffee plantations in the Blue Mountains to coastal waters in Eastern Jamaica. Environ Monit Assess 54:125-141. doi:10.1023/A:1005806815959
Şekercioğlu C, Daily GC, Ehrlich PR (2004) Ecosystem consequences of bird declines. Proc Natl Acad Sci USA 101:18042-18047. doi:10.1073/pnas.0408049101

Soto-Pinto L, Perfecto I, Castillo-Hernandez J, Caballero-Nieto J (2000) Shade effect on coffee production at the northern Tzeltal zone of the state of Chiapas, Mexico. Agric Ecosyst Environ 80:61-69. doi:10.1016/S0167-8809(00) 00134-1

Soto-Pinto L, Perfecto I, Caballero-Nieto J (2002) Shade over coffee: its effects on berry borer, leaf rust, and spontaneous herbs in Chiapas, Mexico. Agrofor Syst 55:37-45. doi:10.1023/A:1020266709570

SPSS Inc (2004) SPSS Base 13.0 for Windows user's guide. SPSS Inc, Chicago

Staver C, Guharay F, Monterroso D, Muschler RG (2001) Designing pest-suppressive multistrata perennial crop systems: shade-grown coffee in Central America. Agrofor Syst 53:151-170. doi:10.1023/A:1013372403359

Van Bael SA, Philpott SM, Greenberg R, Bichier P, Barber NA, Mooney KA, Gruner DS (2008) Birds as predators in tropical agroforestry systems. Ecology 89:928-934. doi: 10.1890/06-1976.1

Vandermeer JH (2003) Tropical agroecosystems. CRC Press, Boca Raton

Williams-Guillén K, Perfecto I, Vandermeer J (2008) Bats limit insects in a tropical agroforestry system. Science 320:70. doi:10.1126/science.1152944

Wrigley G (1988) Coffee. Longman Scientific Technical and John Wiley \& Sons, Inc, New York, p 639

Wunderle JM (1999) Avian distribution in Dominican shade coffee plantations: area and habitat relationships. J Field Ornithol 70:58-70

Wunderle JM, Waide RB (1993) Distribution of overwintering Nearctic migrants in the Bahamas and Greater Antilles. Condor 95:904-933. doi:10.2307/1369428 